\title{
Intestinal botulism
}

INSERM

\section{Source}

INSERM. (1999). Orphanet: an online rare disease and orphan drug data base. Intestinal botulism. ORPHA:178481

Intestinal botulism is a rare form of botulism (see this term), a rare acquired neuromuscular junction disease with descending flaccid paralysis caused by botulinum neurotoxins (BoNTs), and is due to intestinal colonization by Clostridium botulinum leading to toxin-mediated infection with toxemia. The disease affects infants (infant botulism; see this term) and very rarely adults (adult intestinal botulism; see this term). 